\title{
Endobronchial Biopsies in the Diagnosis of Lung Lesions - A Study of 204 Consecutive Cases from a Single Center in Southern India
}

\author{
Nirmala Jyothi, Monalisa Hui, Shantveer G. Uppin, N. Narendra Kumar ${ }^{1}$, K. Bhaskar'1, G. K. Paramjyothi ${ }^{1}$ \\ Departments of Pathology and 'Pulmonology, Nizam's Institute of Medical Sciences, Hyderabad, Telangana, India
}

Abstract

Objectives: The objective of this study is to evaluate the diagnostic yield of endobronchial biopsy in various neoplastic and nonneoplastic lung lesions. Patients and Methods: A total number of 204 consecutive cases of fiberoptic bronchoscopic-guided endobronchial biopsies was analyzed. The bronchial wash (BW) samples collected simultaneously during the biopsy were correlated with final histopathology diagnosis. Results: The bronchoscopic findings mainly included endobronchial mass, increased mucosal vascularity, and mucosal irregularities. Of the 184 adequate biopsy samples, $32.3 \%$ were neoplastic, $20.5 \%$ nonneoplastic, and remaining $41.3 \%$ revealed normal histology. The nonneoplastic lesions included mainly nonspecific inflammation, granulomatous inflammation followed by few cases of squamous metaplasia, one case each of tracheobronchopathia osteochondroplastica, mycobacterium spindle cell pseudotumor, and cytomegalovirus infection. Among the malignant tumors, adenocarcinoma (ADC) was the most common followed by squamous cell carcinoma (SQCC) and non-small cell carcinoma-not otherwise specified. On immunohistochemistry, Napsin-A showed better sensitivity than thyroid transcription factor-1 for ADC. P40 was found to be most sensitive and specific markers for SQCC. Neuroendocrine tumors included seven small cell carcinoma and three carcinoids. Both chromogranin and synaptophysin were found to be equally sensitive neuroendocrine markers. The bronchoscopically normal airways mostly revealed normal histology with few showing mild nonspecific inflammation. On the contrary, all except one case of neoplasm had mass lesions on bronchoscopy. Conclusion: EBB provides sufficient tissue for morphological and immunohistochemical characterization of malignant lesions. BW cytology has poor concordance with EBB in the diagnosis of malignancies with nearly $70 \%$ cases being false negative.

Keywords: Bronchial wash, endobronchial biopsy, immunohistochemistry

\section{INTRODUCTION}

The tracheobronchial tumors represent only $0.6 \%$ of all pulmonary tumors. ${ }^{[1]}$ The nonneoplastic diseases of the central airways are uncommon and may be infectious, postinfectious, posttraumatic, inflammatory, or idiopathic. Diagnosis may be difficult with standard chest radiography because of poor imaging technique. Although computed tomography improves the detection and characterization of central airways, fiberoptic bronchoscopy (FOB) allows careful inspection of the bronchial tree for endobronchial lesions. It is a safe and effective technique for sampling endobronchial lesions for tissue diagnosis. Transbronchial and endobronchial biopsy procedures are of limited invasiveness and are associated with lesser morbidity and mortality than the wedge lung biopsy, which is performed by thoracoscopy

\begin{tabular}{|l|l|}
\hline \multicolumn{2}{|c|}{ Access this article online } \\
\hline Quick Response Code: & Website: \\
\hline & www.ijrc.in \\
\cline { 2 - 2 } & \\
\hline
\end{tabular}

or open surgery. Endoscopic bronchial biopsy (EBB) is useful in the diagnosis of endobronchial tumors and interstitial lung diseases such as sarcoidosis in comparison to other minimally invasive techniques such as bronchial washings (BW) and bronchial brushings (BB). ${ }^{[2]}$ It provides a better diagnostic accuracy of central lung lesions by providing the tissue for further studies such as immunohistochemistry (IHC) and molecular testing. The purpose of this study was to evaluate

Address for correspondence: Dr. Shantveer G. Uppin, Department of Pathology, Nizam's Institute of Medical Sciences, Punjagutta, Hyderabad - 500 082, Telangana, India. E-mail: drsguppin@yahoo.co.in

This is an open access journal, and articles are distributed under the terms of the Creative Commons Attribution-NonCommercial-ShareAlike 4.0 License, which allows others to remix, tweak, and build upon the work non-commercially, as long as appropriate credit is given and the new creations are licensed under the identical terms.

For reprints contact: WKHLRPMedknow_reprints@wolterskluwer.com

How to cite this article: Jyothi N, Hui M, Uppin SG, Kumar NN, Bhaskar K, Paramjyothi GK. Endobronchial biopsies in the diagnosis of lung lesions - A study of 204 consecutive cases from a single center in Southern India. Indian J Respir Care 2021;10:57-65.

Received: 01-07-2020 Accepted: 08-08-2020

Revised: 23-07-2020 Published: 31-01-2021 
the diagnostic yield of EBB in various neoplastic and nonneoplastic lung lesions.

\section{Patients and Methods}

All consecutive cases of FOB-guided EBB submitted for histopathology from January 2016 to May 2018 were included in the study. The relevant clinical and other information were retrieved from the medical records. This was a combined retrospective and prospective study, and the study was approved by the Institutional Ethics Committee.

Of the total 204 biopsies, majority (180 patients; 88\%) were performed by trained pulmonologists of our hospital. The remaining $24(12 \%)$ were referral cases who had biopsies done outside. All the biopsies were done under direct visualization through FOB. Details of procedure-related complications, if any were collected wherever available. The bronchoscopy findings were collected from the medical records.

Routine hematoxylin and eosin $(\mathrm{H}$ and $\mathrm{E})$-stained slides of all the cases were reviewed by two pathologists to confirm the diagnosis. The initial morphological diagnosis was made blinded to the results of special stains and IHC results. Special stains performed included Ziehl-Neelsen (ZN) stain for acid-fast bacilli (AFB), Gomori's Methenamine silver for fungi, and Alcian-PAS for mucin. The results of special stains were reviewed wherever performed.

IHC results were reviewed wherever performed. All IHCs were performed on fully automated immunostainer (Xmatrx; Biogenex) by Poly HRP technique. The primary antibody panel used was determined by initial morphological impression. In general, the antibodies used are provided in Table 1. All the biopsies with adequate materials were divided based on nonneoplastic and neoplastic etiology. The nonneoplastic lesions were further subdivided into nonspecific and specific inflammation, squamous metaplasia, and others. Of the neoplastic lesions, all cases of non-small cell carcinoma (NSCC) were categorized as per recently proposed IASLC/ATS/ERS classification for small biopsies. ${ }^{[3]}$ The cytological findings of the BW samples collected simultaneously during the biopsy were also analyzed. The cytological findings of all these were correlated with final histopathology diagnosis made on EBB.

\section{RESULTS}

Theage of the patients ranged from 11 to 90 years (median, 56years) with an male: female ratio of 2.3:1. Nearly half (100 patients) of them were active smokers, with all of them being males. The most common presentation was cough with or without expectoration $(184 ; 90.2 \%)$ followed by dyspnea $(180 ; 88.2 \%)$, fever $(36 ; 17.6 \%)$, chest pain $(36 ; 17.6 \%)$, and hemoptysis $(23$; $11.3 \%)$ loss of weight/appetite $(17 ; 8.3 \%)$, hoarseness of voice $(2 ; 0.9 \%)$. Ten patients were asymptomatic.

Of the total 180 patients who underwent biopsy in our hospital, $88(43 \%)$ lesions bled on touch during the procedure. The most common complication observed in postprocedure period included hypoxemia in 95 (46\%) followed by hemoptysis in $38(19 \%)$ cases. All the patients with postprocedure-related hypoxemia showed spontaneous resolution after being kept for the short period under the observation. Among the patients who had hemoptysis, 5 required endotracheal tube insertion to clear the airways. These patients were kept under observation for $24 \mathrm{~h}$ and managed conservatively. More than $2 / 3^{\text {rd }}(144 / 204)$ of the biopsies were from the right side most commonly involving the right middle lobe bronchus followed by the right lower lobe bronchus.

The bronchoscopic findings mainly included endobronchial mass in $70(34.3 \%)$, increased mucosal vascularity $39(19.1 \%)$ cases, and mucosal irregularities $21(10.2 \%)$ cases. Mucoid and purulent secretions were seen in $14(6.8 \%)$ cases each and compressed airways in $2(0.9 \%$ ) cases. Nearly $21.5 \%$ (44 cases) of the cases were reported to have normal airways.

\section{Pathology findings}

Of the 204 biopsies, 20 (9.8\%) were considered inadequate/nondiagnostic. Of these 20 inadequate biopsies, 11 biopsies showed only scrapings of superficial epithelium, 8 showed only blood clot with no tissue, and one biopsy was markedly crushed, and hence was not suitable for interpretation. Of the remaining 184 biopsies, 76 (41.3\%) showed normal histology, 42 (22.8\%) nonneoplastic, and 66 (35.8\%) neoplastic.

\section{Nonneoplastic lesions}

The nonneoplastic cases diagnosed included mainly nonspecific inflammation (19 cases) and granulomatous

Table 1: Primary antibody panel used in the study

\begin{tabular}{lll}
\hline & Antibody panel* & Remarks \\
\hline Squamous cell carcinoma markers & P63, P40, CK5/6 & These antibodies were used either alone or in combination \\
Adenocarcinoma markers & TTF-1, Napsin A, CK7, CK20 & These antibodies were used either alone or in combination \\
Neuroendocrine markers & CHR, SYN & The antibodies used varied based on known/unkown primary \\
Mesenchymal markers & SMA, S-100, VIM, CD34, Alk & \\
Metastatic tumors & ER, GCDFP-15 & Ki-67 \\
Proliferation marker & Her-2/neu, PanCK, LCA & \\
Others & . &
\end{tabular}

*The IHC panel used varied in each case based on initial morphological impression and availability of antibody. The combination included one or more antibodies both within and across the groups mentioned above. IHC: Immunohistochemistry, CK: Cytokeratin, TTF-1: Thyroid transcription factor-1, HER-2: Human epidermal growth factor receptor 2, PanCK: Pancytokeratin, GCDFP-15: Gross cystic disease fluid protein 15, CHR: Chromogranina, SYN: Synaptophysin, VIM: Vimentin, ER: Estrogen receptor 
Jyothi, et al.: Endobronchial biopsies in the diagnosis of lung lesions

inflammation with or without necrosis (14 cases). The others included six cases of mucosal squamous metaplasia and one case each of cytomegalovirus (CMV) infection, mycobacterial spindle cell pseudotumor, and tracheobronchopathic osteochondroplastica (TBPO). The various nonneoplastic lesions are illustrated in Figure 1. Majority (12/14) of cases with mucosal granulomas showed associated necrosis. Special stains for fungi and AFB were performed in all cases of granulomatous inflammation. AFB was found in only two of these cases. None of the cases showed any evidence of fungi. In two of the cases with nonnecrotic granulomas, the clinical differentials included sarcoidosis and non-Hodgkin's lymphoma due to the presence of mediastinal lymphadenopathy. On bronchoscopy, these two cases showed extrinsic compression of the airways and on biopsy granulomas were seen just beneath the lining epithelium.

One of the patients diagnosed with mycobacterial spindle-cell pseudotumor was a 35-year-old postrenal transplant female on triple immunosuppression. Biopsy showed the sheets of spindle-shaped histiocytes were laden with numerous AFB on ZN stain. This case morphologically mimicked a benign spindle-cell neoplasm. However, in view of immunosuppressed state, special stains for AFB and fungi were performed in this case.

The single reported case of CMV infection was in 71-year-old female patient with concomitant thymoma (type AB). She had presented with fever, cough, and shortness of breath of 1-month duration. Bronchoscopy revealed mucosal irregularities in bilateral lower lobe bronchi and biopsy showed intranuclear inclusions highlighted with anti-CMV antibodies. Lymphocyte subset analysis of peripheral blood by flow cytometry done later on this revealed complete absence of B-cells.

We also encountered an uncommon case of TBPO in a 38 -year-old male presenting with chronic dry cough of 2 months' duration. Bronchoscopy in this patient revealed the presence of mucosal irregularities spread throughout the tracheobronchial system with a clinical suspicion of TBPO and amyloidosis. The biopsy showed respiratory epithelium with the areas of squamous metaplasia and underlying nodules of the bone with central fatty marrow in the submucosa.

\section{Neoplasms}

Almost all neoplastic cases (65/66) diagnosed during the study period were malignant except for an isolated case of benign nerve sheath tumor. Of these, all were primary epithelial malignancies of lung except one case of endobronchial metastasis from breast carcinoma. The distribution of malignant tumors and their IHC findings are provided in Table 2 and Figures 2, 3.

Primary adenocarcinomas (ADCs) of the lung were the most common accounting for more than $1 / 3^{\text {rd }}(23 / 65)$ of all the malignancies. Of these, 14 cases were categorized as ADC on initial $\mathrm{H}$ and $\mathrm{E}$ morphology without the aid of IHC or special stains. These cases showed evidence of glandular differentiation such as acinar, papillary, and/or micropapillary architecture. The remaining nine cases were morphologically

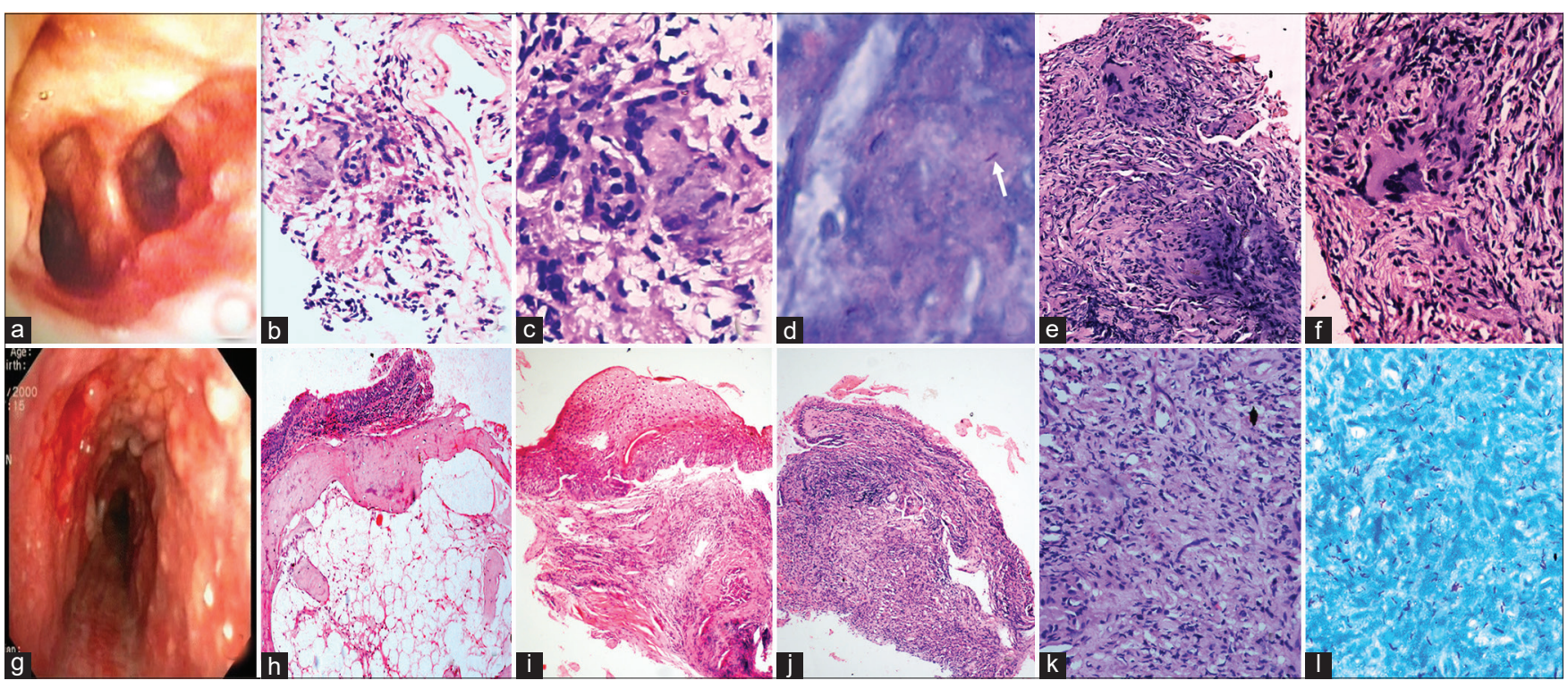

Figure 1: (a) Endobronchial mucosal irregularities on fiberoptic bronchoscopy; (b-d) Necrotizing Granulomatous Inflammation: (b and c) Granulomas comprising of aggregates of epithelioid histiocytes and giant cells ( $\mathrm{H}$ and $\mathrm{E} ; \mathrm{b} \times 100$ and $\mathrm{c} \times 400$ ); (d) acid fast bacilli (indicated by arrow) in a necrotic background (ZN; $\times 400)$; (e and f) Ulcerated mucosa with sub epithelial ill-defined aggregates of epitheliloid cells and multinucleate giant cells ( $\mathrm{H}$ and $\mathrm{E} ; \mathrm{e} \times 100$ and $\mathrm{f} \times 400)$; ( $\mathrm{g}$ and $\mathrm{h}$ ) Tracheobronchopathiaosteochondroplastica: $(\mathrm{g})$ Endobronchial nodules in anterolateral wall of trachea, sparing the posterior tracheal membrane; (h) Bronchial mucosa with focal areas of squamous metaplasia shows a subepithelial nodule comprised of mature bone with central fatty marrow $(\mathrm{H}$ and $\mathrm{E} ; \times 100)$; (i) squamous metaplasia $(\mathrm{H}$ and $\mathrm{E} ; \times 100)$; (j-I) Mycobacterial Spindle cell pseudo tumor: ( $\mathrm{j}$ and $\mathrm{k}$ ) Ulcerated bronchial mucosa with underlying lesion showing spindle shaped histiocytes $(\mathrm{H}$ and $\mathrm{E} ; \mathrm{j} \times 100$ and $\mathrm{k} \times 400)$; (l) Histiocytes are laden with AFB (ZN; ×400) 


\begin{tabular}{|c|c|c|c|}
\hline $\mathrm{H}$ and $\mathrm{E}$ diagnosis & Number & $\begin{array}{l}\text { Final diagnosis } \\
\text { after IHC* }\end{array}$ & Number \\
\hline Epithelial tumors & & Epithelial tumors & \\
\hline High grade dysplasia & 1 & High grade dysplasia & 1 \\
\hline $\mathrm{ADC}$ & 14 & $\mathrm{ADC}$ & 14 \\
\hline SQCC & 16 & SQCC & 16 \\
\hline \multirow[t]{3}{*}{ NSCC-NOS } & 22 & NSCC favour ADC & 9 \\
\hline & & NSCC favour SQCC & 1 \\
\hline & & NSCC-NOS & 11 \\
\hline $\begin{array}{l}\text { NSCC with spindle } \\
\text { cells }\end{array}$ & 1 & $\begin{array}{l}\text { NSCC with spindle } \\
\text { cells }\end{array}$ & 1 \\
\hline Small cell carcinoma & 7 & Small cell carcinoma & 7 \\
\hline Carcinoid & 3 & Carcinoid & 3 \\
\hline \multirow[t]{3}{*}{$\begin{array}{l}\text { Adenoid cystic } \\
\text { carcinoma }\end{array}$} & 1 & $\begin{array}{l}\text { Adenoid cystic } \\
\text { carcinoma }\end{array}$ & 1 \\
\hline & & Metastatic tumors & \\
\hline & & $\begin{array}{l}\text { Metastatic breast } \\
\text { carcinoma** }\end{array}$ & 1 \\
\hline Total & 65 & Total & 65 \\
\hline \multicolumn{4}{|c|}{$\begin{array}{l}\text { *IHC was not done in all cases. In such cases where IHC was not done } \\
\text { initial morphological diagnosis was considered as final diagnosis, } \\
* * 1 \text { case of NSCC-NOS was later categorised as metastatic breast ca. } \\
\text { based on clinical history and IHC findings. H and E: Hematoxylin and } \\
\text { eosin, IHC: Immunohistochemistry, ADC: Adenocarcinoma, SQCC: } \\
\text { Squamous cell carcinoma, NSCC: Nonsmall cell carcinoma, IHC: } \\
\text { Immunohistochemistry }\end{array}$} \\
\hline
\end{tabular}

poorly differentiated, hence were initially categorized as NSCC-not otherwise specified (NOS). These cases were later designated with "NSCC favor ADC" category due to positivity for ADC markers with negative staining for squamous cell carcinoma (SQCC) markers on IHC.

SQCC accounted for nearly a quarter (17/65) of malignant cases. All these except one showed morphological evidence of squamous differentiation such as intercellular bridges, keratinization, and/or pearls and were diagnosed with SQCC on initial $\mathrm{H}$ - and E-stained slides itself. The remaining one was poorly differentiated, initially categorized as NSCC-NOS was found to be positive for SQCC marker with $\mathrm{ADC}$ markers being negative. This case was later categorized as "NSCC favor SQCC."

The cases morphologically categorized as NSCC-NOS, $11 / 65(16.9 \%)$ were poorly differentiated without any evidence of squamous or glandular differentiation. In eight of these cases IHC was not performed, two cases where IHC was performed were negative for both SQCC and ADC markers. In remaining one case, only p40 was available for interpretation which was negative. In rest of the IHC slides, no tissue was represented due to exhaustion of tiny tissue from the block.

Ten neuroendocrine tumors diagnosed included seven small cell lung carcinomas (SCLC) and three carcinoids. All the cases of SCLC showed typical morphology and were confirmed on IHC. The three cases of carcinoid showed neuroendocrine growth pattern of nests, trabecular and focal rossetting. All the three cases had IHC confirmation.
Apart from the above, there was one case of poorly differentiated carcinoma with spindle cells which was categorized as "NSCC with spindle cell" and one adenoid cystic carcinoma. The isolated case of endobronchial metastasis was from breast carcinoma in known and treated case of carcinoma breast. The single benign nerve sheath tumor diagnosed was comprised of spindle cells in short fascicles and patternless sheets and confirmed on IHC ruling out other possibilities.

\section{Immunohistochemistry findings}

The IHC findings of malignant tumors are listed in Table 3. Among the morphologically differentiated ADCs, majority showed positivity for thyroid transcription factor-1 (TTF-1) and Napsin wherever these markers were tested. Of the two ADCs which were negative for TTF-1, 1 was positive for Napsin-A, and the remaining 1 was negative for both. This case showed positivity for CK-7. None of the tested cases of ADCs showed positive staining with $\mathrm{p} 40$, whereas p63 was positive in $1 / 3$ cases of ADCs tested.

Among the poorly differentiated ADCs categorized after IHC as 'NSCC favor ADC' also majority of tested were positive for TTF-1 and Napsin-A. Of the 2 which were negative for TTF-1, 1 was positive for Napsin-A, and the remaining 1 was negative for both. This case showed positivity for CK-7. None of the tested cases of this group showed positive staining with $\mathrm{p} 40$, whereas $\mathrm{p} 63$ was positive in $1 / 4$ cases tested.

All the tested SQCC including one case categorized as "NSCC favor SQCC" showed positivity for $\mathrm{p} 40$ and $\mathrm{p} 63$. None of these stained for ADC markers TTF-1 and Napsin-A. Many cases that finally retained in "NSCC-NOS" category included those cases of poorly differentiated carcinoma where IHC had not been performed.

The isolated case of "NSCC with spindle cells" was negative for SQCC markers (p40, p63, and Ck5/6), ADC markers (TTF-1 and Napsin-A), and neuroendocrine markers (chromogranin and synaptophysin). This case showed positivity only for pancytokeratin and vimentin.

All three cases of carcinoid were positive for chromogranin and synaptophysin. Two of these cases tested for TTF-1 showed negative staining. In two of these Ki67 labelling index of $1 \%$ and remaining one had slightly higher index of $4 \%$. All the tested small-cell carcinomas showed positivity for chromogranin, synaptophysin, and TTF-1. Napsin-A and p63 were negative in these tumors. Ki67 labeling index in these ranged from $35 \%$ to $60 \%$.

The single case of endobronchial metastasis from breast carcinoma was negative for TTF-1, Napsin-A, GCDFP-15, ER, and Her2neu. Metastasis was favored in this case based on clinical history, morphology of tumor, and negative staining for lung ADC markers TTF-1 and Napsin-A.

The case diagnosed with benign nerve sheath tumor showed diffuse strong positivity for S-100 but was negative for SMA, 


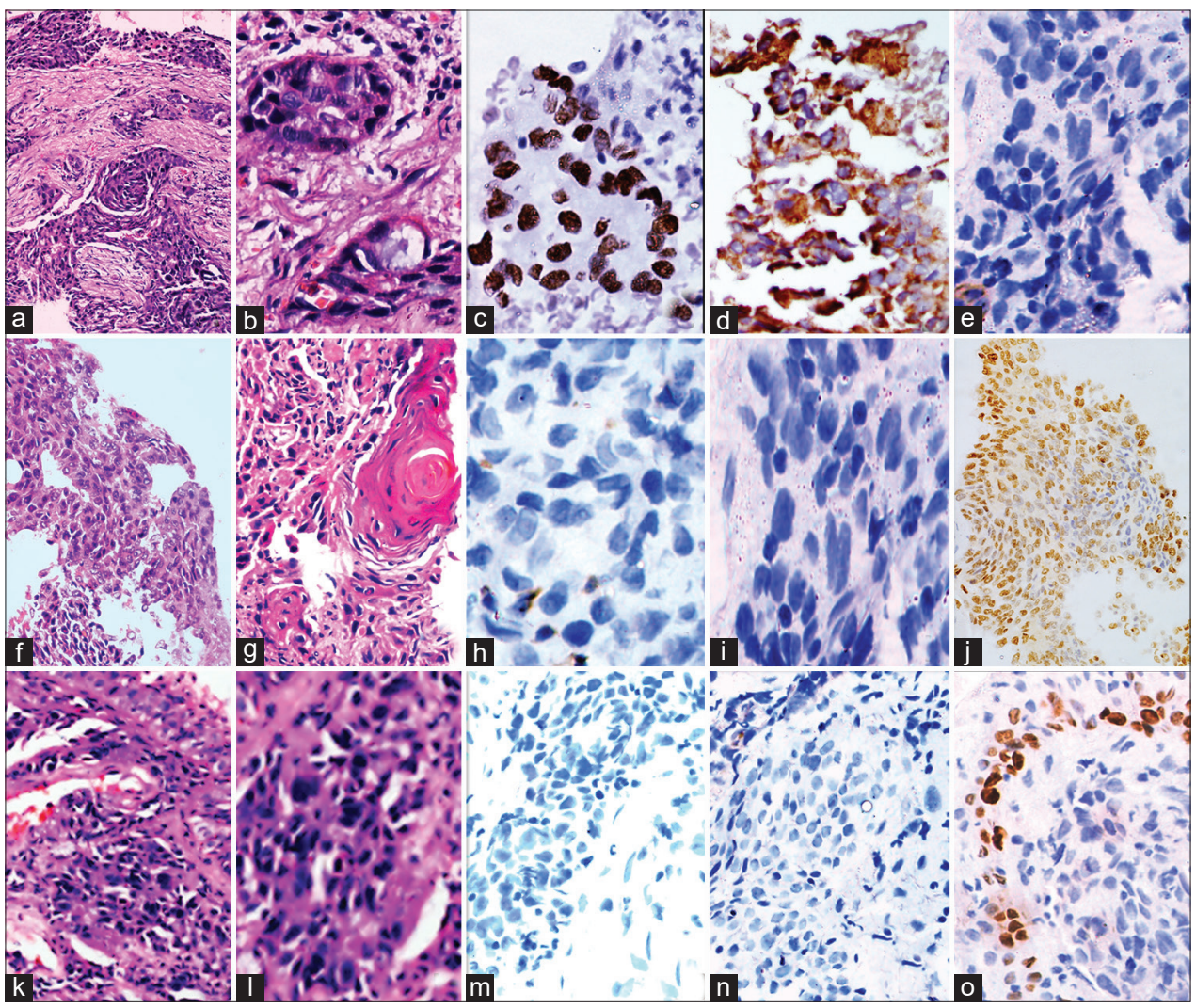

Figure 2: (a-e) Adenocarcinoma: (a) Nests and trabeculae of cells in subepithelium ( $\mathrm{H}$ and $\mathrm{E} ; \times 100)$; (b) Gland formation and intracytoplasmic mucin (H and E; $\times 400$ ); tumor cells are positive for (c) Thyroid transcription factor-1 and (d) Napsin-A and negative for (e) p40 (poly HRP, $\times 400)$; (f-j) Squamous cell carcinoma: ( $f$ and g) Polygonal cells with intracellular keratinization and keratin pearl formation $(\mathrm{H}$ and $\mathrm{E} ; \mathrm{f} \times 100$ and $g \times 400)$; Cells are negative for (h) Thyroid transcription factor- 1 and (i) Napsin-A and positive for (j) p-40.(poly HRP, $\times 400)$; (k-0) nonsmall cell carcinoma not otherwise specified: ( $k$ and I) Bronchial mucosa infiltrated by cells with pleomorphic hyperchromatic nucleus. $(\mathrm{H}$ and $\mathrm{E} ; \mathrm{k} \times 100$ and I $\times 400)$; Cells are negative for (m) thyroid transcription factor-1; (n) Napsin-A; and p40 (poly HRP, ×400)

\begin{tabular}{|c|c|c|c|c|c|c|c|c|c|c|c|c|c|}
\hline & $\begin{array}{c}\text { Number } \\
(\%)\end{array}$ & $\begin{array}{c}\text { TTF-1 } \\
(\%)\end{array}$ & $\begin{array}{c}\text { Napsin } \\
(\%)\end{array}$ & $\begin{array}{l}\text { P63 } \\
(\%)\end{array}$ & $\begin{array}{l}\text { P40 } \\
(\%)\end{array}$ & $\begin{array}{c}\text { CK5/6 } \\
(\%)\end{array}$ & $\begin{array}{l}\text { CHR } \\
(\%)\end{array}$ & $\begin{array}{l}\text { SYN } \\
(\%)\end{array}$ & $\begin{array}{c}\text { Ki-67 } \\
(\%)\end{array}$ & $\begin{array}{l}\text { CK7 } \\
(\%)\end{array}$ & $\begin{array}{c}\text { CK20 } \\
(\%)\end{array}$ & $\begin{array}{c}\text { PanCK } \\
(\%)\end{array}$ & $\begin{array}{l}\text { VIM } \\
(\%)\end{array}$ \\
\hline $\mathrm{ADC}$ & 14 & $\begin{array}{l}8 / 10 \\
(80)\end{array}$ & $\begin{array}{l}9 / 10 \\
(90)\end{array}$ & $\begin{array}{l}1 / 3 \\
(33)\end{array}$ & $\begin{array}{l}0 / 8 \\
(0)\end{array}$ & $0 / 1(0)$ & $\begin{array}{l}0 / 2 \\
(0)\end{array}$ & $\begin{array}{l}0 / 1 \\
(0)\end{array}$ & - & $\begin{array}{c}2 / 2 \\
(100)\end{array}$ & $\begin{array}{l}0 / 2 \\
(0)\end{array}$ & - & - \\
\hline SQCC & 16 & $0 / 6$ & $0 / 4$ & $\begin{array}{c}5 / 5 \\
(100)\end{array}$ & $\begin{array}{c}6 / 6 \\
(100)\end{array}$ & - & - & - & - & - & - & - & - \\
\hline NSCC favour ADC & 9 & $\begin{array}{l}6 / 8 \\
(75)\end{array}$ & $\begin{array}{l}5 / 6 \\
(83)\end{array}$ & $\begin{array}{l}1 / 4 \\
(25)\end{array}$ & $\begin{array}{l}0 / 7 \\
(0)\end{array}$ & - & $\begin{array}{l}0 / 3 \\
(0)\end{array}$ & $\begin{array}{l}0 / 3 \\
(0)\end{array}$ & - & $\begin{array}{c}1 / 1 \\
(100)\end{array}$ & - & - & - \\
\hline NSCC favour SQCC & 1 & $\begin{array}{l}0 / 1 \\
(0)\end{array}$ & $0 / 1(0)$ & $\begin{array}{c}1 / 1 \\
(100)\end{array}$ & $\begin{array}{c}1 / 1 \\
(100)\end{array}$ & - & - & - & - & - & - & - & - \\
\hline NSCC-NOS & 11 & $\begin{array}{l}0 / 2 \\
(0)\end{array}$ & $0 / 2(0)$ & $\begin{array}{l}0 / 2 \\
(0)\end{array}$ & $\begin{array}{l}0 / 2 \\
(0)\end{array}$ & $0 / 1(0)$ & $\begin{array}{l}0 / 1 \\
(0)\end{array}$ & $\begin{array}{l}0 / 1 \\
(0)\end{array}$ & - & - & - & $\begin{array}{c}1 / 1 \\
(100)\end{array}$ & - \\
\hline NSCC with spindle cells & 1 & $\begin{array}{l}0 / 1 \\
(0)\end{array}$ & $0 / 1(0)$ & - & $\begin{array}{l}0 / 1 \\
(0)\end{array}$ & $0 / 1(0)$ & $\begin{array}{l}0 / 1 \\
(0)\end{array}$ & $\begin{array}{l}0 / 1 \\
(0)\end{array}$ & 22 & - & - & $\begin{array}{c}1 / 1 \\
(100)\end{array}$ & $\begin{array}{c}1 / 1 \\
(100)\end{array}$ \\
\hline Small cell carcinoma & 7 & $\begin{array}{c}5 / 5 \\
(100)\end{array}$ & $0 / 4(0)$ & $\begin{array}{l}0 / 3 \\
(0)\end{array}$ & - & - & $\begin{array}{c}5 / 5 \\
(100)\end{array}$ & $\begin{array}{c}5 / 5 \\
(100)\end{array}$ & $35-60$ & - & - & - & - \\
\hline Carcinoid & 3 & $\begin{array}{l}0 / 2 \\
(0)\end{array}$ & - & - & - & - & $\begin{array}{c}3 / 3 \\
(100)\end{array}$ & $\begin{array}{c}3 / 3 \\
(100)\end{array}$ & $1-4$ & - & - & - & - \\
\hline $\begin{array}{l}\text { Metastatic breast } \\
\text { carcinoma** }\end{array}$ & 1 & $\begin{array}{l}0 / 1 \\
(0)\end{array}$ & $0 / 1(0)$ & - & - & - & - & - & - & - & - & - & - \\
\hline
\end{tabular}

**In addition to the above, this case was negative for ER, HER-2/neu and GCDFP-15. ADC: Adenocarcinoma, SQCC: Squamous cell carcinoma, NSCC: Nonsmall cell carcinoma, CHR: Chromogranina, SYN: Synaptophysin, PanCK: Pancytokeratin, VIM: Vimentin, ER: Estrogen receptor, NOS: Not otherwise specified, GCDFP-15: Gross cystic disease fluid protein 15, HER-2: Human epidermal growth factor receptor 2, CK: Cytokeratin, TTF-1: Thyroid transcription factor-1 
Jyothi, et al.: Endobronchial biopsies in the diagnosis of lung lesions

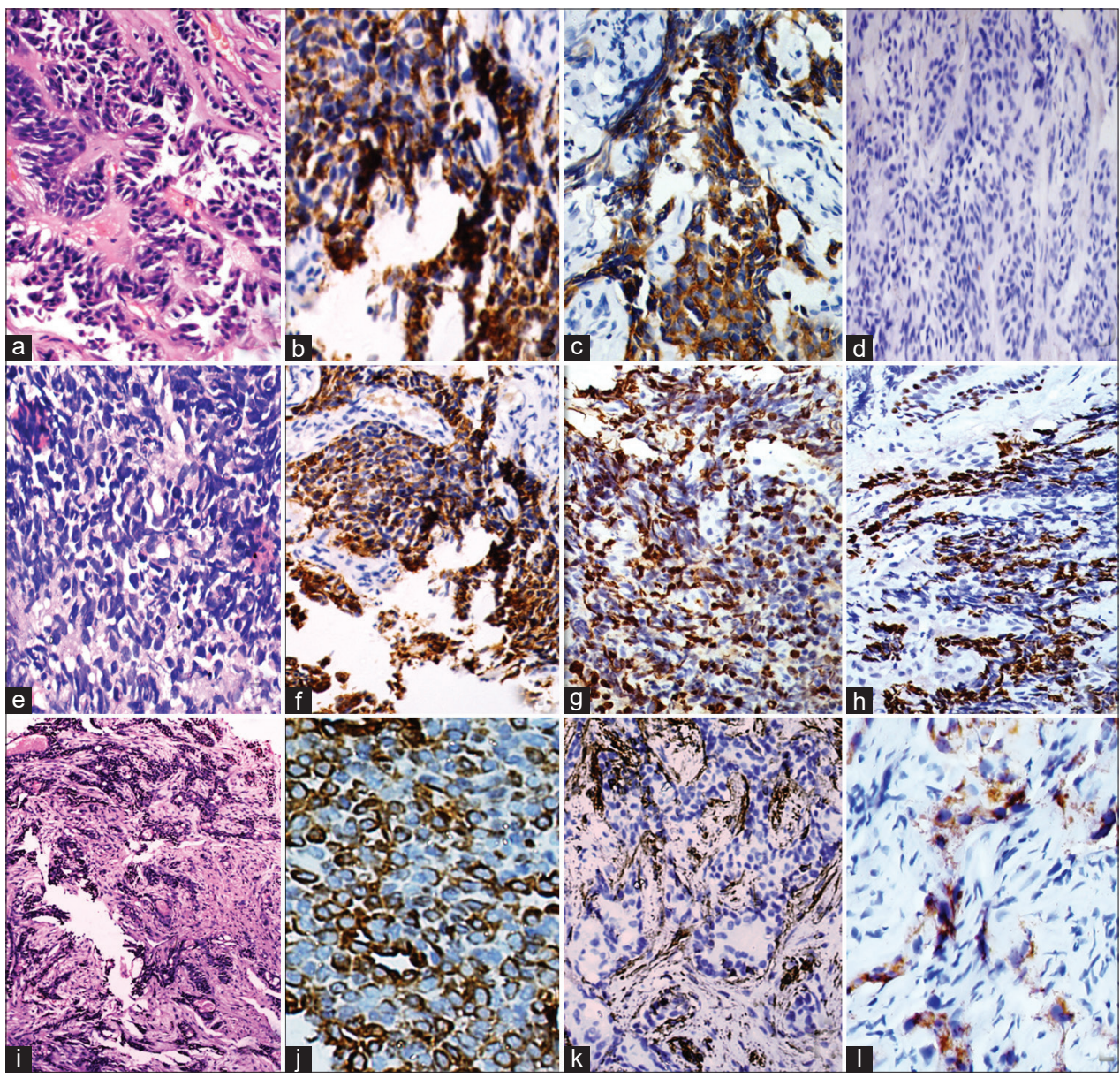

Figure 3: (a-d) Endobronchial carcinoid: (a) Cells arranged in nests and papillae with uniform round to oval nucleus. $(\mathrm{H}$ and $\mathrm{E} ; \times 100)$, Tumor cells showed positivity for (b) chromogranin; (c) synaptophysin; (d) ki-67 labelling index was 1\% (poly HRP, $\times 400)$, (e-h) Small cell carcinoma: (e) Sheets of small round cells with scant cytoplasm and hyperchromatic nucleus with nuclear overlapping and molding (H and E; 100); Tumor cells were positive for (f) Chromogranin, (e) Synaptophysin, and (f) Thyroid transcription factor-1-positive (poly HRP, $\times 400$ ); (i-I) Adenoid cystic carcinoma: (i) Tumor cells arranged in tubules and cribriform pattern ( $\mathrm{H}$ and $\mathrm{E} ; \times 100)$; (j-k) CK7 positive in epithelial cells and SMA positive in myoepithelial cells (poly HRP; j $\times 400$ and $\mathrm{k} \times$ 100); (I) CD117 focally positive in the tumor cells; (polyHRP; $\times 100$ )

CD34, ALK, and pancytokeratin. Ki-67 labeling index in this tumor was $0.5 \%$.

\section{Correlation between bronchoscopy findings and final diagnosis}

More than $80 \%(36 / 44)$ of patients reported to have normal airways on bronchoscopy showed normal histology, and the rest showed nonspecific inflammation. Other categories which showed predominantly normal histology were cases with increased mucoid or watery secretions and increased mucosal vascularity on bronchoscopy. Some the cases from the latter group showed nonspecific inflammation or mucosal squamous metaplasia. Almost all cases with purulent secretions on bronchoscopy showed inflammatory pathology, especially specific inflammation. Cases which showed mucosal irregularities on bronchoscopy showed either normal histology or inflammatory pathology. All except one case of neoplasm reported were in patients who had mass lesions on bronchoscopy. The two cases reported to have nonnecrotic granulomas showed extrinsic airway compression on bronchoscopy. These patients had mediastinal lymphadenopathy and were clinically suspected to have either sarcoidosis or lymphoma.

\section{Correlation between bronchial wash findings and final diagnosis}

During the study period, of the total 204 patients who underwent EBB, 174 (85\%) had simultaneous BWs submitted for pathology examination. Of these, majority (147/174) were reported as "negative for malignancy." Of these, 20 showed evidence significant inflammation (suppurative - 10, AFB positive -9 , and fungi -1 ). Of the remaining, 26 cases were "positive for malignancy" with remaining 1 case being reported to have inadequate material for opinion. Correlation between the final diagnosis on EBB and bronchoscopic findings and BWs is provided in Tables 4 and 5 .

BW findings were available in 123/138 nonneoplastic cases (including inadequate biopsies) reported on EBB. Of these, nearly $91 \%$ (112 cases) showed concordance and were reported "negative for malignancy." Among these, nine samples were positive for AFB, and these included four cases of normal 
Jyothi, et al.: Endobronchial biopsies in the diagnosis of lung lesions

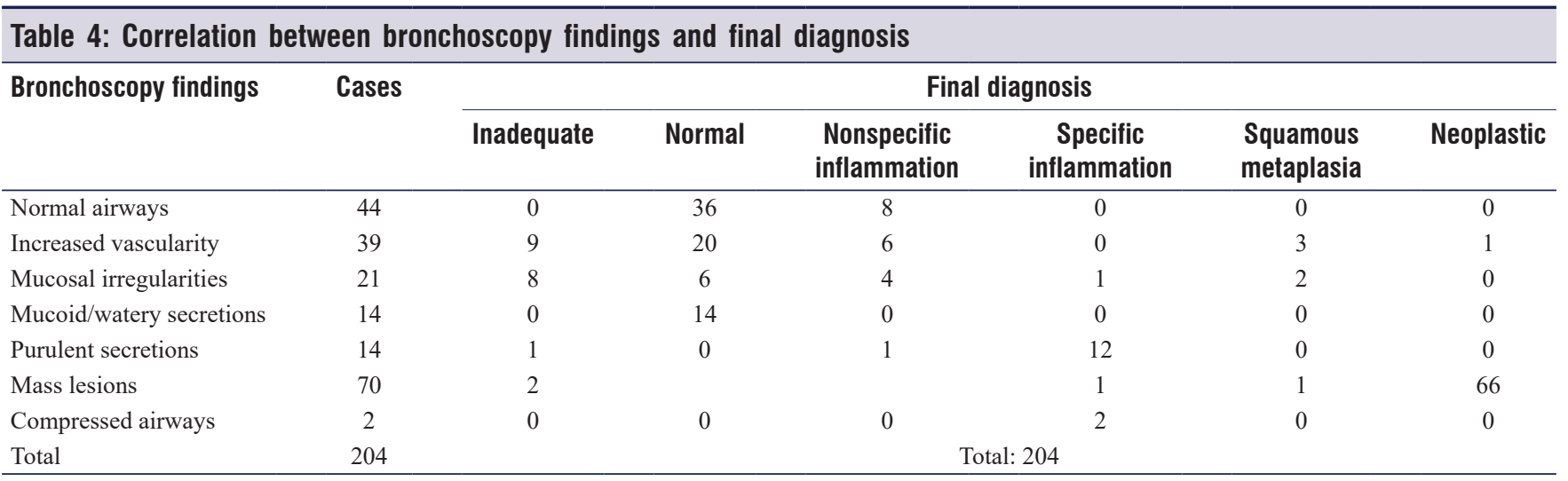

Table 5: Correlation between bronchial wash findings and final diagnosis

\begin{tabular}{|c|c|c|c|c|c|c|c|c|}
\hline & Number & Not available & NEM & Suppurative & Kochs & Fungal & Malignant & Inadequate \\
\hline Inadequate biopsy & 20 & 5 & 11 & 0 & 0 & 0 & 4 & 0 \\
\hline Normal & 76 & 9 & 53 & 4 & 4 & 0 & 5 & 1 \\
\hline Nonspecific inflammation & 19 & 0 & 15 & 3 & 0 & 0 & 1 & 0 \\
\hline Granulomatous inflammation & 14 & 0 & 8 & 2 & 4 & 0 & 0 & 0 \\
\hline $\mathrm{CMV}$ & 1 & 0 & 1 & 0 & 0 & 0 & 0 & 0 \\
\hline Mycobacterial spindle cell psuedotumour & 1 & 0 & 0 & 0 & 1 & 0 & 0 & 0 \\
\hline Squamous metaplasia & 6 & 1 & 4 & 1 & 0 & 0 & 0 & 0 \\
\hline TBOP & 1 & 0 & 1 & 0 & 0 & 0 & 0 & 0 \\
\hline $\mathrm{ADC}$ & 14 & 4 & 5 & 0 & 0 & 0 & 5 & 0 \\
\hline SQCC & 16 & 5 & 9 & 0 & 0 & 0 & 2 & 0 \\
\hline NSCC & 21 & 2 & 11 & 0 & 0 & 1 & 7 & 0 \\
\hline NSCC with spindle cells & 1 & 0 & 1 & 0 & 0 & 0 & 0 & 0 \\
\hline Small cell carcinoma & 7 & 2 & 4 & 0 & 0 & 0 & 1 & 0 \\
\hline Carcinoid & 3 & 1 & 2 & 0 & 0 & 0 & 0 & 0 \\
\hline Adenoid cystic carcinoma & 1 & 0 & 1 & 0 & 0 & 0 & 0 & 0 \\
\hline Metastatic breast carcinoma & 1 & 0 & 0 & 0 & 0 & 0 & 1 & 0 \\
\hline High grade dysplasia & 1 & 1 & 0 & 0 & 0 & 0 & 0 & 0 \\
\hline Benign nerve sheath tumor & 1 & 0 & 1 & 0 & 0 & 0 & 0 & 0 \\
\hline Total & 204 & 30 & 127 & 10 & 9 & 1 & 26 & 1 \\
\hline
\end{tabular}

CMV: Cytomegalovirus, TBOP: Tracheobronchopathia osteochondroplastica, NEM: No evidence of malignancy, ADC: Adenocarcinoma, SQCC:

Squamous cell carcinoma, NSCC: Non-small cell carcinoma

biopsy, four of granulomatous inflammation, and one case of mycobacterial spindle cell pseudotumor reported on endobronchial biopsies. Of the ten discordant cases which were reported "positive for malignancy" on BW cytology, 4 were inadequate biopsies, 5 showed normal histology, and the remaining one case showed only nonspecific inflammation on biopsy.

Of the total 66 neoplastic lesions reported on EBB, BW findings were available in 51 cases. If the single case of benign nerve sheath tumor is excluded, then only 16 (31\%) of the remaining 50 malignant cases were also reported "positive for malignancy" on cytology. In the remaining 35 (69\%) malignant cases, BW cytology was falsely negative.

\section{Discussion}

FOB is an essential diagnostic and therapeutic procedure which enables sampling techniques such as BB, BW, bronchoalveolar lavage, EBB, transbronchial biopsy, and transbronchial needle aspiration. The complications of FOB are well-known but are rare. In the present study, the postprocedure complication was seen in overall $65.1 \%(133 / 204)$ patients with hypoxemia being the most common followed by hemoptysis. Rates of specific complications reported in the literature show wide variations, with reported incidence of hypoxia ranging from 0.7 to $76.3 \%$ of patients and bleeding in $2.5 \%-89.9 \%$ of patients. ${ }^{[4-7]}$

The yield of EBB varies with type of endobronchial lesion detected at bronchoscopy. In the present study, most of patients with normal findings, increased mucosal vascularity, or mucoid/ watery secretions on bronchoscopy showed either normal finding $(72 \%)$ or nonspecific inflammation (19\%). On the contrary, majority of patients with endobronchial abnormalities such as mass lesions, mucosal irregularities, purulent secretion, and extrinsic compressions (85\%) show specific pathological findings. Among the patients presenting with endobronchial mass lesions, the diagnostic yield was $94.3 \%$ with almost all of 
them being neoplasms. Ghazarian et al. reported the diagnostic yield of EBB in all lesions to be $81.1 \%$ and in cases of visible endobronchial masses to be $100 \%{ }^{[8]}$

Bhadke et al. reported bronchoscopy to be diagnostic in $75 \%$ patients. In contrast to our study where we encountered the greater number of neoplastic lesions (62.3\%) than nonneoplastic $(37.7 \%)$ lesions, a reverse trend was noted in their study accounting for $64 \%$ nonneoplastic and $31 \%$ neoplastic lesions. The diagnostic material in the present study included EBB and BW, whereas Bhadke et al. included bronchoscopic aspirates, brushing, and biopsy. ${ }^{[9]}$

In the study of 50 cases of endobronchial tuberculosis by Altin et al., mass lesions were found in 31 cases $(62 \%)$, while $11(22 \%)$ cases had submucosal infiltrative appearance, $16(32 \%)$ fibro stenosis, and $5(10 \%)$ hyperemia and edema. ${ }^{[10]}$ In the present study, granulomatous inflammation with or without necrosis (14 cases) showed purulent secretions on bronchoscopy in most of the cases. Two of the cases clinically suspected to be sarcoidosis presented with extrinsic compression of airways. The incidence of endobronchial CMV infection is rare. Naber et al. reported three such cases of presenting as bronchial polyps in lung transplant recipients. ${ }^{[1]}$ The isolated case encountered in the present study was a known cases of thymoma (type $\mathrm{AB}$ ) and showed mucosal irregularity on bronchoscopy without any evidence of polyps. Mycobacterial spindle cell pseudotumors are most commonly identified in the lymph nodes, skin, spleen, or bone marrow of immunocompromised patients and only rarely involve the lungs. Boylan et al. reported three such cases which included 2 HIV-positive individuals. ${ }^{[12]}$ TBPO is an uncommon benign lesion with characteristic bronchoscopic findings. In the present study, though the diagnosis was considered on bronchoscopy, EBB was performed to rule out amyloidosis.

Almost all neoplastic lesions encountered in the present study were epithelial malignancies. Pulmonary ADC was the most common histological type (35.4\%), followed by SQCC (26.2\%), NSCC-NOS (16.9\%), and small cell carcinoma $(10.8 \%)$. In a study done in West China, the proportion of ADC increased from 25.93\% (1995-1997) to $56.36 \%$ (2013-2015); however, the proportion of SQCC decreased from $49.1 \%$ to $26.34 \%$. The proportion of SCLC cases declined from $1995-1997$ to $2013-2015$. $^{[13]}$

Majority of NSCCs can be subtyped on routine $\mathrm{H}$ - and E-stained slides alone, difficulty is encountered in poorly differentiated tumors, especially in small biopsy specimens. IHC helped in subtyping total 11 out of 22 cases of NSCC-NOS initially diagnosed on $\mathrm{H}$ and $\mathrm{E}$ morphology into nine cases of ADC, 1 case each of SQCC and metastatic breast carcinoma. Of the remaining 11, IHC was not performed in 8, 2 remained unclassified even after IHC and remaining 1 case had incomplete IHC work-up.

IHC was not done in all cases and the combination of markers used varied between the cases. Among the
ADC markers, Napsin-A showed better sensitivity than TTF-1 (87.5\% vs. $77.8 \%)$. The present study results are in agreement with those reported by Tacha et al. wherein they showed sensitivity of TTF-1 and Napsin to be $69 \%$ and $88 \%$, respectively. ${ }^{[14]} \mathrm{CK} 7$ helped in categorizing two cases as ADC where both TTF-1 and Napsin were negative. Mukhopadhyay and Katzenstein in their study designed to assess the utility of an IHC panel containing TTF-1, Napsin A, p63, and CK5/6 for the subclassification of poorly differentiated NSCC reported a sensitivity of $80 \%$ for TTF-1 and 58\% for Napsin A. ${ }^{[15]}$ Both P63 and P40 showed 100\% sensitivity in SQCC. P40 was found to be absolutely specific for SQCC and stained none of the ADCs, but P63 stained 2/7 (28.6\%) ADCs, thereby reducing its specificity. Many studies have shown both P63 and P40 to be highly sensitive SQCC markers, but the reported specificities for $\mathrm{P} 40$ has ranged from 90 to $100 \%$ whereas that for P63 from 51 to 97\%. ${ }^{[16-18]}$

Both chromogranin and synaptophysin showed equally high sensitivity in all of the SCLC and carcinoids tested. Carcinoids are known to be strongly and diffusely positive for commonly used NE markers (synaptophysin, chromogranin A, and CD56/NCAM). ${ }^{[19]}$ In a small minority of carcinoid tumors, particularly in atypical carcinoids, not all NE markers may be expressed, and therefore, a panel approach has to be used. ${ }^{[20]}$ TTF-1 positivity has been reported in approximately $50 \%$ of lung carcinoids. TTF-1 expression which is typically strong and diffuse in ADC or SCLC, the labelling in carcinoid tumors is reported to be weak and focal. In the present study, 2 of three carcinoids tested for TTF-1 were negative. Synaptophysin and chromogranin A show weak staining in SCLC in contrast to robust reactivity typical of carcinoid tumors. CD56 is considered to be the least specific NE marker at other sites, but is reported to be most sensitive NE marker for SCLC. About a quarter of SCLCs are reported to be negative for both synaptophysin and chromogranin A, but most of these tumors are positive for CD56. ${ }^{[21]}$ In the present study, CD56 was not studied.

On comparison of bronchoscopy with the final diagnosis on EBB, the present study showed most endobronchial mass $(94.2 \%)$ lesion detected on bronchoscopy are neoplastic with almost all being malignant. Rabahi et al. also concluded that endobronchial mass is the most common bronchoscopic finding that is suggestive of malignancy. ${ }^{[22]}$

Several studies have reported increased efficacy for combined use of cytological findings and biopsy. Dobler et al. concluded that the addition of BB and BW significantly increased the diagnostic yield when compared to biopsy alone. ${ }^{[23]}$ In the present study, only BW was available for the correlation with EBB. In the present study, also BW picked up 10 additional cases of malignancy which were missed by EBB. In addition, BW was positive for AFB in 6 additional cases not reported on EBB. On the other hand, BWs was falsely negative in nearly $70 \%$ malignant cases reported on EBB. 
Jyothi, et al:: Endobronchial biopsies in the diagnosis of lung lesions

\section{Conclusion}

Most of bronchoscopically normal airways do not show significant pathology hence may not require biopsy unless there is a strong clinical indication. Most of the mass lesion on bronchoscopy harbors malignancy hence need to be biopsied. Endobronchial biopsy provides sufficient tissue for morphological and immunohistochemical characterization of malignant lesions which is essential for the management of lung carcinomas in the present era of targeted therapy. BW cytology has poor sensitivity for the diagnosis of endobronchial malignancies with high false-negative rates.

\section{Financial support and sponsorship}

Nil.

\section{Conflicts of interest}

There are no conflicts of interest.

\section{References}

1. Stevic R, Milenkovic B. Tracheobronchial tumors. J Thorac Dis 2016;8:3401-13.

2. Du Rand IA, Blaikley J, Booton R, Chaudhuri N, Gupta V, Khalid S, et al. British thoracic society guideline for diagnostic flexible bronchoscopy in adults: Accredited by NICE. Thorax 2013;68 Suppl 1:i1-44.

3. Travis WD, Brambilla E, Noguchi M, Nicholson AG, Geisinger KR, Yatabe $\mathrm{Y}$, et al. International association for the study of lung cancer/American thoracic society/European respiratory society international multidisciplinary classification of lung adenocarcinoma. J Thorac Oncol 2011;6:244-85.

4. Rosell A, Xaubet A, Agustí C, Castella J, Puzo C, Curull V, et al. A new BAL fluid instillation and aspiration technique: A multicenter randomized study. Respir Med 2006;100:529-35.

5. Gibson PG, Breit SN, Bryant DH. Hypoxia during bronchoalveolar lavage. Aust N Z J Med 1990;20:39-43.

6. Carr IM, Koegelenberg CF, von Groote-Bidlingmaier F, Mowlana A, Silos K, Haverman T, et al. Blood loss during flexible bronchoscopy: A prospective observational study. Respiration 2012;84:312-8.

7. Leiten EO, Martinsen EM, Bakke PS, Eagan TM, Grønseth R. Complications and discomfort of bronchoscopy: A systematic review. Eur Clin Respir J 2016;3:33324.

8. Ghazarian Z, Alziadat M, Sekhon R, Hanna M, Pandya T, Ismail M. Diagnostic yield of bronchoscopic lung biopsy in evaluating lung cancer. Chest 2016;150:710A.

9. Bhadke B, Munje R, Mahadani J, Surjushe A, Jalgaonkar P. Utility of fiberoptic bronchoscopy in diagnosis of various lung conditions: Our experience at rural medical college. Lung India 2010;27:118-21.

10. Altin S, Cikrikçioğlu S, Morgül M, Koşar F, Ozyurt H. 50 endobronchial tuberculosis cases based on bronchoscopic diagnosis. Respiration 1997;64:162-4.

11. Naber JM, Palmer SM,Howell DN Cytomegalovirus infection presenting as bronchial polyps in lung transplant recipients. J Heart Lung Transplant 2005;24:2109-13.

12. Boylan KE, Larsen BT, Young BA, Downs-Kelly E, Panchabhai TS, Collum ES, et al. Pulmonary mycobacterial spindle cell pseudotumor: A report of 3 cases including a practical approach to histopathologic recognition of this unusual entity. Int J Surg Pathol 2018;26:629-34.

13. Zhang X, Wu L, Xu Y, Zhang B, Wu X, Wang Y, et al. Trends in the incidence rate of lung cancer by histological type and gender in Sichuan, China, 1995-2015: A single-center retrospective study. Thorac Cancer 2018;9:532-41.

14. Tacha D, Bremer R, Haas T, Qi W. An immunohistochemical analysis of a newly developed, mouse monoclonal p40 (BC28) antibody in lung, bladder, skin, breast, prostate, and head and neck cancers. Arch Pathol Lab Med 2014;138:1358-64.

15. Mukhopadhyay S, Katzenstein AL. Subclassification of non-small cell lung carcinomas lacking morphologic differentiation on biopsy specimens: Utility of an immunohistochemical panel containing TTF-1, napsin A, p63, and CK5/6. Am J Surg Pathol 2011;35:15-25.

16. Bishop JA, Teruya-Feldstein J, Westra WH, Pelosi G, Travis WD, Rekhtman N. p40 ( $\triangle \mathrm{Np} 63)$ is superior to p63 for the diagnosis of pulmonary squamous cell carcinoma. Mod Pathol 2012;25:405-15.

17. Ming-Hui AO, Zhang H, Sakowski L, Sharma R, Illei PB, Gabrielson E, et al. The utility of a novel triple marker (combination of TTF1, napsin A, and p40) in the subclassification of non-small cell lung cancer, Hum Pathol 2014;45:926-34.

18. Dvorak K, Yambert J, Palting J, Reinhardt K, Roessler C, Moh A, et al. Improved lung cancer classification using new optimized immunohistochemical assay with anti-p40 (BC28) mouse monoclonal antibody. Int J Clin Exp Pathol 2016;9:2693-01.

19. Rekhtmann N. Neuroendocrine tumors of the lung. Arch Pathol Lab Med 2010;134:1628-38.

20. Beasley MB, Thunnissen FB, Brambilla E, Hasleton P, Steele R, Hammar SP, et al. Pulmonary atypical carcinoid: Predictors of survival in 106 cases. Hum Pathol 2000;31:1255-65.

21. Hiroshima K, Iyoda A, Shida T, Shibuya K, Iizasa T, Kishi H, et al. Distinction of pulmonary large cell neuroendocrine carcinoma from small cell lung carcinoma: a morphological, immunohistochemical, and molecular analysis. Mod Pathol 2006;19:1358-68.

22. Rabahi MF, Ferreira AA, Reciputti BP, Matos Tde O, Pinto SA. Fiberoptic bronchoscopy findings in patients diagnosed with lung cancer. J Bras Pneumol 2012;38:445-51.

23. Dobler CC, Crawford AB. Bronchoscopic diagnosis of endoscopically visible lung malignancies: Should cytological examinations be carried out routinely? Intern Med J 2009;39:806-11. 